\title{
MESCLA GENÉRICA E FORMA EDITORIAL NOS EPIGRAMAS BUCÓLICOS ATRIBUÍDOS A TEÓCRITO $^{1}$ \\ GENERIC MIXTURE AND EDITORIAL FORM IN BUCOLIC EPI- GRAMS ASCRIBED TO THEOCRITUS
}

Alexandre Pinheiro Hasegawa ${ }^{2}$

Resumo: Proponho-me neste artigo investigar as marcas editorias presentes na primeira seção dos epigramas atribuídos a Teócrito (1-6), não observadas nem por Gutzwiller (1998) nem por Rossi (2001); estudo também nestes poemas as mesclas genéricas como característica fundamental da $\sigma u \lambda \lambda$ oүฑ่. Palavras-chave: livro antigo; gêneros de poesia; epigrama; espécie bucólica; Teócrito.

Abstract: I propose in this article to investigate the editorial marks present in the first section of the epigrams ascribed to Theocritus (1-6), that haven't been observed by Gutzwiller (1998) nor by Rossi (2001); In this poems I study also generic mixtures as a fundamental characteristic of

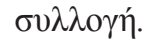

Keywords: ancient books; poetic genres; epigram; bucolic species; Theocritus.

Os monarcas e filólogos helenísticos tinham o desejo de colecionar coisas (objetos de arte, livros e até mesmo animais) ${ }^{3}$, desejo que se concretiza, de maneira exemplar, na Biblioteca de Alexandria, onde se procurava reunir todos os livros do mundo ${ }^{4}$. Pode-se dizer, analogamente, que a $\alpha v \theta$ o $\lambda$ oүía é como que uma biblioteca que reúne, seletivamente, epigramas próprios e de outros, como as Guirlandas de Meléagro de Gádara ${ }^{5}$ e de Filipe da Tessalônica. Além desta prática para a circulação dos epigramas, há ainda a $\sigma 0 \lambda \lambda$ oүฑं, em que se recolhem apenas poemas alheios, e o libellus, que é a recolha da própria produção poética ${ }^{6}$.

\footnotetext{
Agradeço a leitura, correções e sugestões de Alexander Sens e João Angelo Oliva Neto.

Doutor em Letras Clássicas pela USP. Professor de Língua e Literatura Latina da FFLCH/USP.

Ver Krevans 2007: 131, com bibliografia e as referências antigas.

Para a Biblioteca de Alexandria, ver Canfora 1993: 19-22.

Para a Guirlanda de Meléagro, remeto a Gutzwiller 1998: 276-322.

6 Para a distinção e exemplificação, ver Argentieri 1998: 2, que assim resume: "Sintetizzando
} 
O epigrama, de modo particular, está estreitamente ligado à circulação em formato de livro, fruto dessas práticas arroladas acima, por duas razões, como explica Argentieri, quando distingue os três tipos de coleções epigramáticas (1998: 1): primeiro, a brevidade desta poesia deve sua sobrevivência por ter sido recolhida; em segundo lugar, a origem do próprio gênero pressupõe a escrita e um suporte material, seja em objeto de ex-voto (epigrama votivo), seja em lápide (epigrama fúnebre) ${ }^{7}$.

Embora a prática da própria edição estivesse já bastante difundida no séc. III a.C., ou seja, o libellus era um modo de circulação comum ${ }^{8}$, parece que Teócrito não editou seus poemas neste formato?. É notável, por exemplo, o fato de Meléagro em seu poema proemial (AP 4.1) mencionar, entre os epigramatistas helenísticos, Calímaco de Sirene (v.

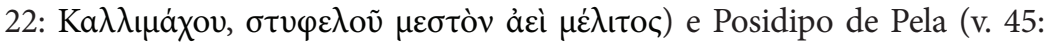

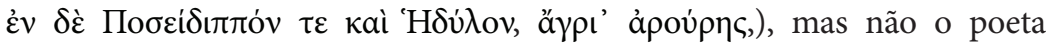
de Siracusa. Portanto, dos 26 epigramas que lhe são atribuídos, os 22 conservados nos manuscritos bucólicos devem ser considerados como uma $\sigma v \lambda \lambda \gamma_{\gamma} \dot{\eta}^{10}$.

A $\sigma 0 \lambda \lambda$ 위 de poemas atribuídos a Teócrito ${ }^{11}$, conservada em alguns manuscritos da família ambrosiana $(\mathrm{KeD})^{12}$, apresenta a seguinte sequência, cuja importância é ressaltada desde Wilamowitz (1906: 113-122) ${ }^{13}$ :

1-6 - epigramas bucólicos ${ }^{14} ; 7-16$ epigramas votivos e tumulares não

con una formula generale, possiamo dire che le raccolte epigrammatiche si dividono in tre tipi: la silloge, in cui si compila senza creare; il libellus, in cui si crea senza compilare; l'anthologia, in cui si compila per creare."

7 Os mais antigos usos da palavra ė $\pi i \gamma \rho \alpha \mu \mu \alpha$ estão relacionados a inscrições funerárias e votivas. Ver Puelma 1997: 190. Para a pré-história do gênero, ver Fantuzzi e Hunter 2002: 389-397.

8 Ver Gutzwiller 1996a: 119.

9 Ver Argentieri 1998: 7; Gutzwiller 1998: 41.

10 Ver Rossi 2001: 361.

11 Sobre a paternidade e datação dos epigramas, ver a discussão em Rossi 2001: 355-359.

12 Ver Gow 1952: 523.

13 Apud Gutzwiller 1996a: 140, n. 66. Desde então segue-se a tripartição dos epigramas, à exceção de Rossi 2001: 367, que propõe separar o epigrama 1 da seção bucólica, porque entende que ele seja proêmio à coleção.

14 Sobre a espécie epigramática bucólica, caracterização que não se encontra em fontes antigas, ver discussão em Rossi 2001: 29-62, com bibliografia. Ao definir bucólicos os epigramas que "deal with the pastoral world and that consequently have as protagonists shepherds, cowherds and goatherds", além da possível presença de ovelhas ou vacas, divindades ligadas ao mundo pastoral, o locus amoenus e a siringe (p. 34), Rossi exclui da seção bucólica o epigrama 1. Adiante voltarei a discutir a classificação deste poema. Porém, para a crítica a essa definição, ver Stanzel 2007: 335, que a considera muito restrita, ao separar rústico e bucólico. Anite é considerada a "inventora" da espécie (ver Rossi 2001: 53; Stanzel 2007: 333). 
bucólicos ${ }^{15} ; 17-22$ - epigramas em diferentes metros, sem o uso do dístico elegíaco ${ }^{16}$ (todos dedicados a poetas à exceção do $20^{17}$ ). Tal disposição, que parece ter paralelo com a dos Idílios preservada no códice PAntinoae (idílios bucólicos em hexâmetros, idílios não bucólicos em hexâmetros e poemas eólicos $)^{18}$, permite pensar a organização interna das três seções ${ }^{19}$, o que pretendo fazer a seguir, limitando-me à primeira (epigramas 1-6), de epigramas bucólicos com o proêmio da recolha.

\section{O Proêmio}

O caráter proemial do epigrama 1 já foi bem comentado pelos estudiosos $^{20}$, assim como o entendimento do poema como inscrição para obra de $\operatorname{arte}^{21}$ já foi questionado ${ }^{22}$. Parece-me, porém, importante aprofundar leitura de Gutzwiller (1998: 43) quanto à imagem das flores em poemas introdutórios de coleções epigramáticas, tais como provavelmente foram AP 9.313 para Anite, AP 6.300 para Leônidas e AP 5.170 para Nósside, e certamente AP 4.1 foi para Meléagro, que associa claramente, na Guirlan$d a$, poetas a flores. Antes de mais nada, flores e árvores assim aparecem no epigrama 1, atribuído a Teócrito:

1 Gow (AP 6. 336 = 5 G.-P.)

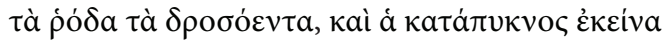

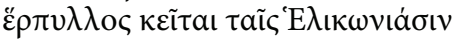

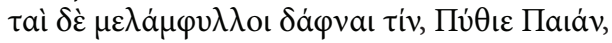

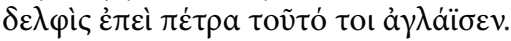

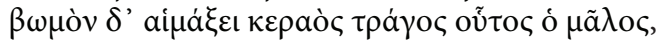

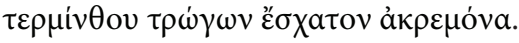

15 À exceção do epigrama 14, ver a discussão sobre as espécies dos epigramas votivos e tumulares em Rossi 2001: 3-13. Para a alternância entre estas espécies, entre o epigrama 7 e o 12, ver Gutzwiller 1998: 44, em que apresenta paralelo com outro livro epigramático, P. Köln 5.204, que contém seis epigramas de Mnasalces.

16 Metro mais frequente no gênero.

1717 dedicado a Anacreonte, 18 a Epicarmo, 19 a Hipônax, 21 a Arquíloco e 22 a Pisandro. Para estudo dos epigramas sobre poetas, ver Rossi 2001: 81-106.

18 Ver discussão em Gutzwiller 1996a: 139-142.

19 Como faz, por exemplo, Gutzwiller 1998: 42-45 e Rossi 2001:367-375.

20 Tarditi 1988: 47; Gutzwiller 1998: 43; Rossi 2001: 124-125; 367. Rossi enfatiza tal caráter e critica a classificação como bucólico.

21 Ver Gow 1952: 527, que considera os três primeiros da mesma maneira.

22 Remeto a Rossi 2001: 65-73. 
As rosas orvalhadas e aquele serpilho

denso são para as Musas do Helicão;

p'ra ti, Pítio Peã, louros de negra folha, pois orna-se com isso a rocha délfica;

este cornuto bode alvo o altar vai manchar, que come do t'rebinto ramo extremo ${ }^{23}$.

De acordo com Gutzwiller (1998: 43), "the use of vegetable symbolism in a preamble to characterize the collected epigrams" teria sido uma prática editorial introduzida já pelos epigramatistas do século III a.C. Como possível exemplo desta prática, a estudiosa norte-americana menciona o epigrama que pode ter introduzido a coleção de Nósside (1 G-P = AP 5.170) ${ }^{24}$ :

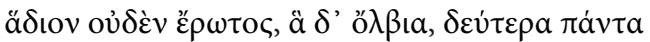

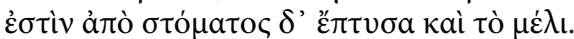

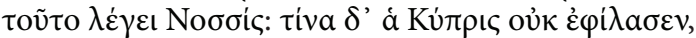

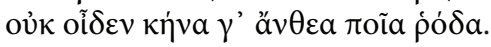

Nada é mais doce do que o amor; todos prazeres vêm depois; mel também cuspi da boca.

Isto diz Nósside: a quem Cípris não amou, não conhece quais rosas são suas flores ${ }^{25}$.

O caráter proemial do epigrama, encabeçando um provável libellus pode ser defendido não só pelo nome da autora, a presença do priamel e

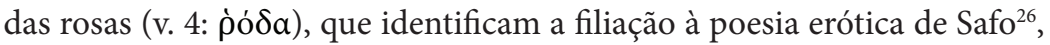

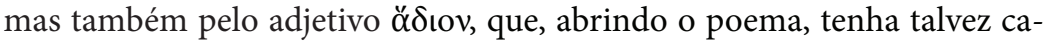
ráter programático. Da mesma maneira, considera-se $A P 5.169$ (= 1 G-P),

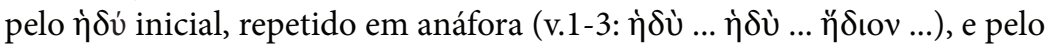
priamel que celebra o amor ${ }^{27}$, o primeiro poema de um possível libellus de

23 As traduções sem indicação de autor são minhas.

24 Ver também Argentieri 1998: 6-7; Gutzwiller 1998: 75-78; Guichard 2004: 75; 142.

25 Sobre a discussão e o entendimento do v. 4, ver Gow and Page 1965: 435-6; Degani 1993: 211, com bibliografia.

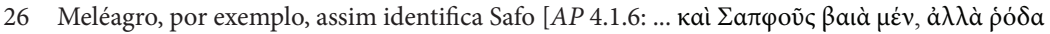
(e poucas flores de Safo, mas rosas)]. O priamel pode retomar o fr.16 V de Safo. Para a relação entre Nósside e Safo, ver também Gow and Page 1965: 434-435. O caráter erótico da

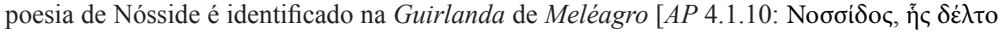

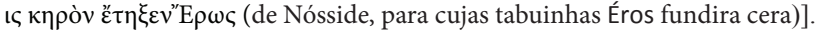

27 Sobre a relação entre os dois epigramas, o de Nósside e de Asclepíades, não se tem certeza qual seria o modelo, mas é provável que um tivesse o poema do outro em mente ao compor (ver Sens 2011: 3). Embora o priamel seja prática comum, como ressalta Sens (2011: 1), 
Asclepíades $^{28}$, que serviu de modelo ao programático Idílio 1 de Teócrito ${ }^{29}$ :

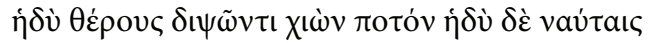

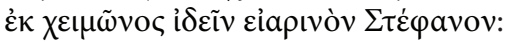

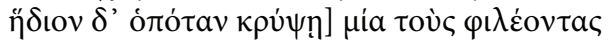

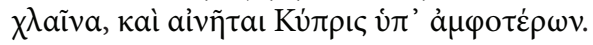

Doce bebida é, no verão, neve ao sedento; ver Guirlanda vernal é doce aos nautas, pós o inverno; mais doce quando uma só manta cubra os amantes e ambos louvem Cípris.

No poema de Asclepíades, embora não haja uma flor específica, men-

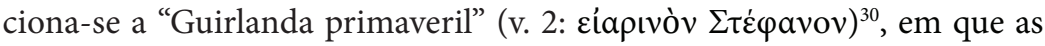

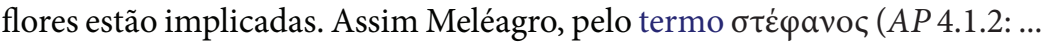

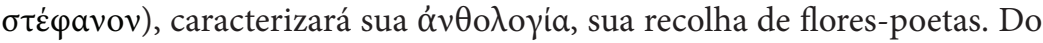
confronto dos epigramas de Nósside e do poeta de Samos, destaco ainda a presença de Afrodite (Kúteıs: AP 5.170.3; AP 5.169.4), que por metonímia significa o amor, matéria destacada nos epigramas, mais doce do que as outras coisas mencionadas.

Vistos os poemas de Nósside e Asclepíades, entendidos como proemiais, sejam de seção de um libellus, seja do próprio libellus, volto ao epigrama 1 atribuído a Teócrito, em que, embora não haja priamel e comparação para ressaltar uma matéria, há dois outros elementos importantes destacados acima: 1) as flores (a rosa mencionada em Nósside e a Guirlanda, em Asclepíades), e 2) a divindade (apenas Afrodite mencionada por ambos).

Em relação ao primeiro aspecto, no epigrama 1, há mais de uma refe-

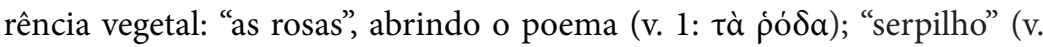

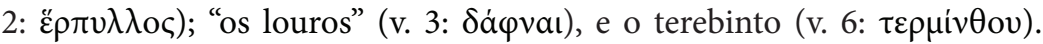
Os três primeiros (rosa, serpilho e louro) são oferendas aos deuses e o

caracteriza, por exemplo, o proêmio da recolha lírica horaciana (carm. 1.1) e o proêmio do segundo livro de Lucrécio (2.1-13), em que se encontram os adjetivos suaue e dulcius (para a comparação com Asclepíades, ver Gutzwiller 1998: 129-130).

28 Ver Gutzwiller 1998: 128-130; Guichard 2004: 139-142; Sens 2011: 2. Para a possibilidade de ser o início de seção, ver Sens 2011: xcii. No entanto, seja proêmio de um livro ou abertura de seção, parece consenso o caráter programático do poema.

29 Ver Gutzwiller 1998: 72; Guichard 2004: 15-17; 142; Sens 2011: 3. O Idílio 1 de Teócrito também é iniciado pelo mesmo adjetivo na forma dórica ( $\grave{\alpha} \delta \dot{u})$, seguido de anáfora (v. 1-7: $\grave{\alpha} \delta \grave{u} . .$.

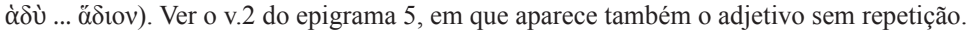

30 É referência à "Guirlanda de Ariadne", "Corona Borealis, whose evening rising early in March might serve to mark the beginning of spring" (Gow and Page 1965: 118). 
último (terebinto) é alimento do bode que será ofertado. A variedade dos vegetais ${ }^{31}$ poderia sugerir, em confronto aos outros epigramas vistos, a $\pi$ roเkı $\lambda i \alpha^{32}$ que caracteriza a recolha desses poemas atribuídos a Teócrito; variedade não só de matéria (votivos e tumulares bucólicos, 1-6, e não bucólicos, 7-16, por exemplo), mas também de metro (terceira seção, 17-22, em que não se usa o dístico elegíaco das duas primeiras seções, variando sempre o esquema métrico).

Quanto ao segundo aspecto, no poema atribuído a Teócrito, há a ofe-

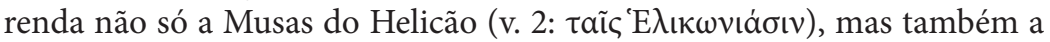

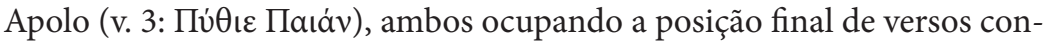
tíguos. Em comparação com os epigramas de Nósside e de Asclepíades, há novamente variedade neste epigrama votivo, ao mencionar as heliconíades e o "Pítio Peã", divindades tutelares da poesia, e não apenas um deus, Afrodite, no caso dos outros dois epigramas analisados.

A presença de Febo e das filhas de Mnemósine merece atenção mais detida. Rossi (2001: 122, n. 9) julga que, embora seja inegável a relação de Apolo com o mundo dos pastores, o "Pítio Peâ" aqui, pela associação com as Musas, só pode ser entendido como deus da poesia ${ }^{33}$. Por outro lado, parece-me inegável também que a presença de Apolo, sem menção às Musas, cumpre papel proemial em âmbito helenístico em diversos gêneros, seja em livros dos próprios poetas, como nas Argonáuticas de Apolônio de

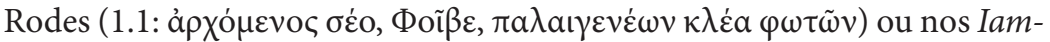

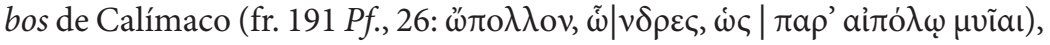
seja na edição helenística dos poetas arcaicos, como a de Alceu feita por

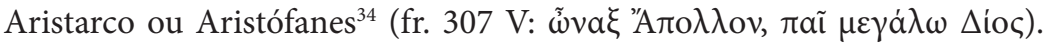
Assim, de fato, embora Rossi (2001: 122) não mencione esses paralelos épico, iâmbico e lírico, a mera presença de Apolo talvez não seja suficiente para caracterizar o epigrama 1 como bucólico. No entanto, a meu ver, se até mesmo o sacrifício do bode ( $\tau \rho a ́ \gamma o \varsigma)$ no dístico final também não o caracterize como bucólico, é possível, ainda assim, elencar outros elementos que apontam para o mundo pastoril.

31 De acordo com Gutzwiller (1998: 43), "post-Meleagrian readers would easily interpret the roses and thyme offered to the Muses and the laurel offered to Apollo as symbols of the poems within the collection, just as the plants mentioned in Meleager's preamble stand for the epigrammatists in his anthology". Para a crítica a essa leitura, ver Rossi 2001: 124-5.

32 Sobre a variedade como princípio na organização das recolhas, ver Gutzwiller 1998: 9-10, com bibliografia, e o paralelo não só com os livros helenísticos, tais como os Iambi de Calímaco, mas também com os livros romanos da época de Augusto, tais como os de Horácio, Virgílio e Propércio.

33 Para a menção das divindades juntas, cita Hesíodo, Teogonia, 94 e ss.

34 Ver Pardini 1991: 259-258. 
Para tanto, é importante, antes de mais nada, entender o epigrama 1 no conjunto da recolha, ou seja, numa $\sigma v \lambda \lambda$ oүń cuja primeira seção é claramente bucólica. Embora a explicação da passagem de um poema a outro, proposta por Gutzwiller (1998: 43-44), tenha problemas ${ }^{35}$, é consensual o entendimento do grupo 2-6 como bucólico. Ora, nesta seção, é clamorosa a presença do poeta-pastor por excelência, Dáfnis, mencionado nos epigramas $2-5$ (2.1, em que o nome abre o poema; $3.1 ; 4.14 ; 5.4)$. E ainda que no estratégico poema 1 Dáfnis não seja explicitamente mencionado, ele é

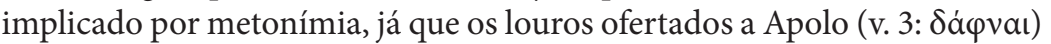
ecoam por paronímia o nome do pastor $(\Delta \dot{\alpha} \varphi v i \varsigma)$, presente por quase toda

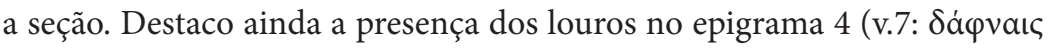

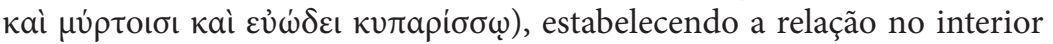
da própria seção bucólica. Por isso, embora associação de Apolo ao louro

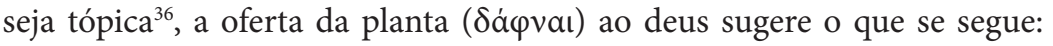
epigramas em que se menciona Dáfnis ( $\Delta$ á $\varphi v i \varsigma)$.

Se, por um lado, a relação de Apolo com o mundo pastoral é bem atestada, não se pode esquecer, por outro, de um vínculo importante na tradição poética entre as Musas e um pastor-poeta: a célebre iniciação de Hesíodo descrita na Teogonia (22-28):

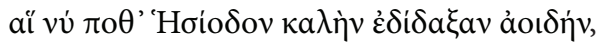

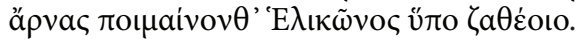

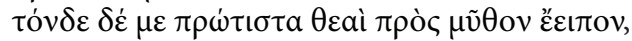

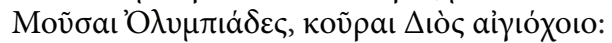

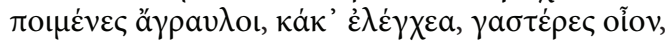

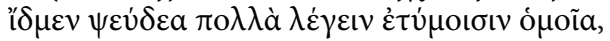

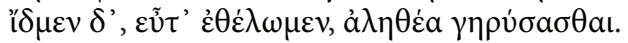

Elas um dia a Hesíodo ensinaram belo canto quando pastoreava ovelhas ao pé do Hélicon divino. Esta palavra primeiro disseram-me as Deusas Musas olimpíades, virgens de Zeus porta-égide:

"Pastores agrestes, vis infâmias e ventres só, sabemos muitas mentiras dizer símeis aos fatos e sabemos, se queremos, dar a ouvir revelações"37.

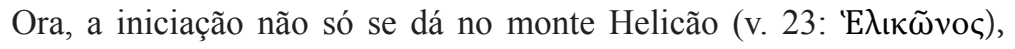

35 Ver Rossi 2001: 368, n.32.

36 Ver Rossi 2001: 364-5, em que contesta algumas imitações virgilianas nos epigramas atribuídos a Teócrito, apontadas por Gutzwiller 1996b: 93-94.

37 Tradução Jaa Torrano em Torrano 1995: 107. 


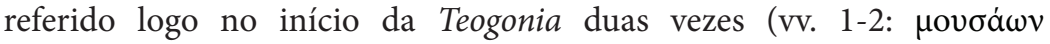

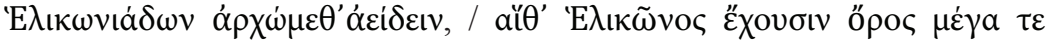

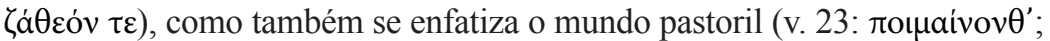

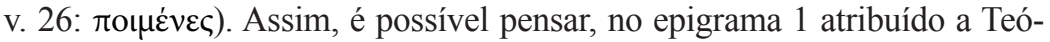

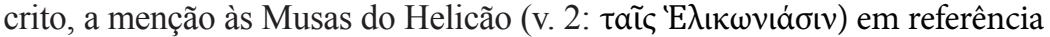
ao mundo pastoril, já que Hesíodo era importante modelo para os poetas helenísticos ${ }^{38}$. Além disso, a presença conjunta das Musas e Apolo no epigra-

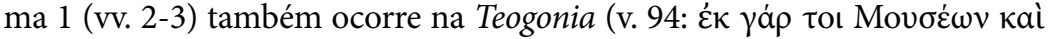

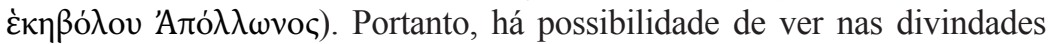
e nas oferendas do epigrama 1 atribuído a Teócrito referência ao mundo pastoril, abrindo a $\sigma v \lambda \lambda$ oүn் e anunciando a primeira seção bucólica cujo primeiro epigrama é também votivo em que Dáfnis, o poeta-pastor por excelência ${ }^{39}$, ao cantar hino bucólico em bela siringe, dedica a Pã as ferramentas de trabalho ${ }^{40}$ :

2 Gow (AP $6.177=6$ G.-P.)

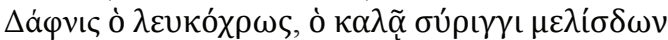

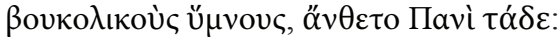

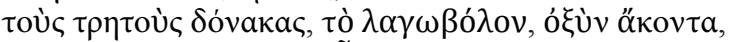

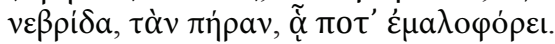

Dáfnis, de branca tez, que em bela sirinx canta bucólico hino, a Pã dedicou isto:

dardo agudo, o cajado, os caniços furados, pele de cervo e alforje pra as maçã̃ ${ }^{41}$.

A abertura da primeira seção, ao imitar os Idílios de Teócrito ${ }^{42}$, insere no epigrama votivo elementos bucólicos ${ }^{43}$, com destaque para o pastor-po-

38 Lembro apenas AP 9.507, epigrama de Calímaco dedicado a Arato, em que louva Hesíodo, que

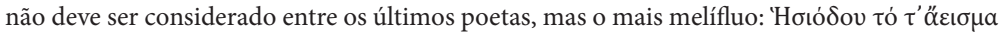

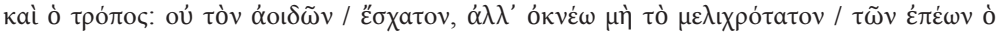

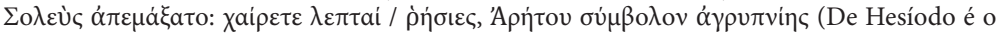
canto e o modo. Temo, não no aedo / último, porém sim na mais melíflua/ épica se moldou o poeta Sólio. Salve / gráceis versos, vigília e afã de Arato. Tradução João Angelo Oliva Neto).

39 Ver Gow 1952: 1-2; Hunter 1999: 60-68; Hasegawa 2012: 36-38; 168. Em oposição a esta tradição parece estar Calímaco ( $A P 7.518=22 P f$.), ao propor cantar o cabreiro Astácides no lugar do vaqueiro Dáfnis. Sobre o epigrama ver Larson 1997; Rossi 2001: 47-48.

40 Ver Gutzwiller 1998: 43.

41 A parte final do último verso: "alforje, em que outrora carregava maçãs".

42 Ver Rossi 2001: 138-139, com destaque para o programático Idílio 1, em que Tírsis canta sobre Dáfnis.

43 A conclusão de Rossi (2001: 137): "In conclusion, this epigram belongs to the bucolic type contaminated with the votive sub-genres of dedications of tools and offerings by mythical 
eta, Dáfnis, primeira palavra da composição e personagem mencionada em quase todos os poemas do conjunto (2-5), como indicado acima. Embora a caracterização da personagem como caçador, pelas oferendas mencionadas, seja estranha na tradição ${ }^{44}$, parece claro tratar-se de epigrama bucólico e ao mesmo tempo votivo, a caracterizar a mescla genérica da $\sigma 0 \lambda \lambda$ o $\gamma \dot{\eta}$.

É importante destacar ainda o verbo com que se encerra esse epigrama:

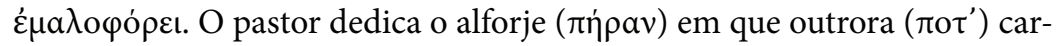
regava as maçãs ( $\varepsilon \mu a \lambda$ o ó$_{\rho} \varepsilon$ ). O fruto em questão tem grande importância no âmbito erótico ${ }^{45}$ e, portanto, é possível ver na última palavra do epi-

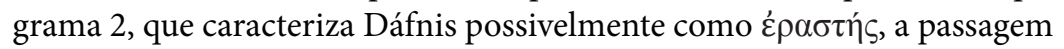
para o seguinte, o epigrama 3, em que a personagem agora é ć $\rho \omega ́ \mu \varepsilon v o \varsigma$, assim como está caracterizado no epigrama 4.

\section{Priapo e a Matéria Erótica}

Ao epigrama em que Dáfnis, caracterizado como caçador, dedica seus instrumentos a Pã, cantando hino bucólico, seguem-se dois em que se introduz matéria erótica ${ }^{46}$ : o primeiro é o epigrama 3, em que Pã e Priapo perseguem, com intenção sexual, o caçador Dáfnis, que dorme; o segundo é o epigrama 4, em que se ordena a um cabreiro que rogue a Priapo para se livrar do amor por Dáfnis:

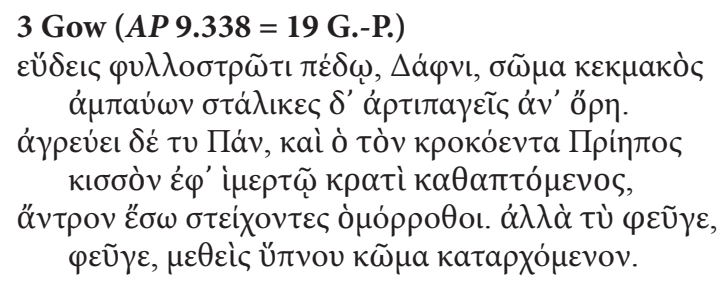

dedicators. Concerning the figure of Daphnis, then, the composition juxtaposes the Theocritean tradition and that probably derived from a source that followed a different version of the myth".

44 Ver discussão em Rossi 2001: 134-137.

45 Ver, por exemplo, Theoc. 3.10; Catul. 65.19; Verg. Ecl. 3.70-71; Prop. 1.3.24. Para outras referências, ver Hunter 1999: 113-114. Na $A P$, ver 5.79 e 5.80, os epigramas eróticos atribuídos a Platão.

46 Gutzwiller (1998: 43) ressalta o tema sexual em 3 e 4: "The fourth poem moves the sexual theme from the gods to the world of a herdsman, who prays for relief from his passion for Daphnis". 
Dormes, Dáfnis; no chão folhado jaz teu corpo lasso; no cume estacas tendem redes.

Mas Pã é quem te caça, com Priapo (a testa linda de hera e açafrão!). Entram na gruta e têm um só intento. Então vai, foge, afasta o sono e este torpor que vêm chegando ${ }^{47}$.

4 Gow $(A P, 9.437=20$ G.-P.)

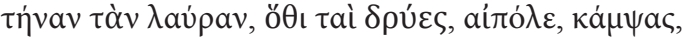

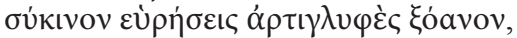

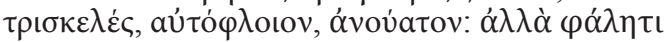

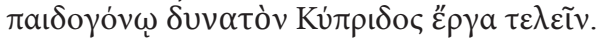

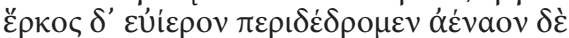

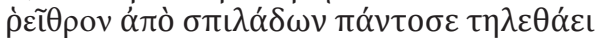

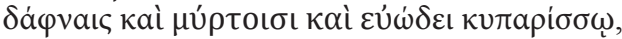

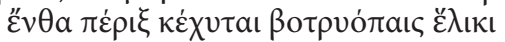

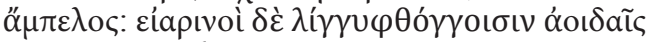

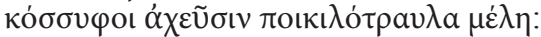

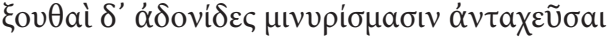

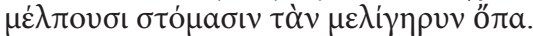

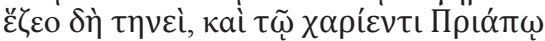

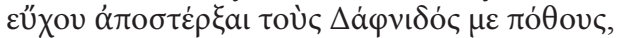

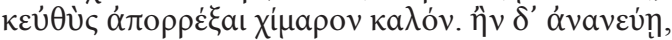

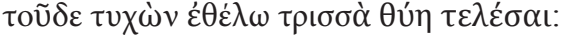

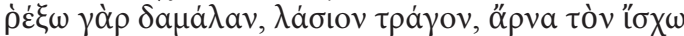

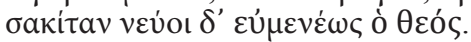

Verás, dobrando aquela trilha onde há carvalhos, cabreiro, um novo entalhe de figueira, tosco, com casca, sem orelha mas, coffalo gera-filho, capaz de encargos Cíprios.

Circunda-lhe sagrada cerca, eterno arroio das penhas flui e em toda parte enflora louros, mirtos, cheirosos ciprestes; e ali em torno a vinha espalha as uvas, suas filhinhas e primaveris ecoam melros canções com voz aguda em mil chilreios.

Sonoros rouxinóis das bocas gorjeantes, soltando a voz de mel, devolvem chilros.

Pois senta lá e roga ao gracioso Priapo que não me toque mais o amor por Dáfnis, que logo um belo bode imolo. Se negar, me dando Dáfnis, triplo é o sacrifício: uma novilha, um bode hirsuto, mais a ovelha, do meu redil: que bem o acolha o deus.

47 A tradução dos epigramas 3 e 4 é de João Angelo Oliva Neto. Apud Oliva Neto 2006: 180-183. 
Rossi, ao discutir a caracterização do epigrama 3 como bucólico, considera anômala a presença de Priapo ${ }^{48}$. Parece-me, desde logo, que a estranheza se dê, apenas se se pensa o poema na tradição epigramática, já que a presença de Priapo no gênero bucólico, relacionado a Dáfnis, ocorre no Idílio 1 de Teócrito duas vezes, uma quando os pastores se sentam

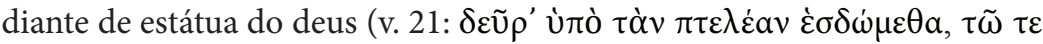
$\Pi \rho ı \eta ் \pi \omega)$, outra quando Priapo comparece no canto de Tírsis dialogando com Dáfnis e rebaixando o boiadeiro em cabreiro (vv. 80-91) ${ }^{49}$. Assim a aparição de Priapo não é anômala em um epigrama bucólico ${ }^{50}$.

Além disso, embora a fonte seja tardia, Nono Abade, em escólio aos Discursos contra Juliano de Gregório de Nazianzo ${ }^{51}$, narra que Priapo foi criado por pastores, o que o caracteriza como personagem bucólica:

"Sobre Priapo, esta é a história: dizem que Afrodite, quando voltou da Etiópia, assumira uma beleza tão incrível, que o próprio Zeus foi tomado de desejo por ela e, unindo-se-lhe, produziu ciúme interminável em Hera. De imediato, então, Hera, pressentindo o que viria e por prever que uma criança nascida de Afrodite superaria em beleza e dominaria todos os filhos de Zeus, agarrou o ventre de Afrodite e, mediante sortilégio, tramou para que a criança nascesse disforme. Nascendo disforme e toda obscena, feia e obesa, a mãe, ao ver que o que havia gerado the traria a maior vergonha, pegou da criança e lançou-a numa montanha. Um pastor ( $\pi 0 \mu \mu \eta ́ v)$, encontrando-a por acaso, apanhou-a e alimentou-a. Julgando que para a fertilidade da terra, dos jumentos e quadrúpedes contribuía a afecção existente naquele ser (refiro-me às partes pudendas: pois tinha-as acima do ânus), depois de o recolher, assentou-o, prestou-lhe honrarias e chamou Priapo, isto é, em língua latina, aquele que, salvo do extravio, salva aqueles que se extraviam nos lugares ermos. Desde então, dizem, Priapo é honrado pelos pastores $(\pi \mathrm{O} \mu \varepsilon \dot{\sigma} \sigma \mathrm{lv})$.

48 Rossi 2001: 147: “... the appearance of Priapus, normally present in epigrams that are rural in context, but completely absent in bucolic ones, is anomalous." Em seguida (p. 151), procura entendê-la em referência ao Idílio 1 de Teócrito.

49 Para Priapo no Idílio, ver Hunter 1999: 74-74; 90-94; Oliva Neto 2006: 326; Hasegawa 2012: 178-179.

50 Ver Rossi 2001: 151.

51 Patrologia Graeca (Migne), 36, 34, 1052-1053, a, b, c: apud Oliva Neto 2006: 66-67. Tradução de João Angelo Oliva Neto; os negritos são meus. 
No entanto, como propõe Oliva Neto (2006: 199) ao tratar da Priapeia Grega, parece haver, tanto no epigrama 3 como no 4, confluência genérica: além da espécie bucólica ${ }^{52}$, o suposto gênero priapeu ${ }^{53}$ e o epigrama pederástico. Porém, como diferença genérica importante de um para o outro, o epigrama 4 também dialoga de modo risível ${ }^{54}$ com a espécie votiva (vv. 13-18 $)^{55}$. Seja como for, o que parece claro não só na recolha geral, mas também nesta primeira parte, é a mescla genérica, presente como princípio de composição importante para os helenísticos e seus seguidores ${ }^{56}$.

Antes de passar ao epigrama 5, é preciso ainda tratar da relação dos três primeiros da seção bucólica (2-4): se no primeiro (epigrama 2) o pastor (Dáfnis) se dirige a um deus (Pã) e no segundo (epigrama 3), inversamente, deuses (Pã e Priapo) se dirigem, com intenção sexual, ao pastor (Dáfnis), agora (epigrama 4) há um pastor (um cabreiro) que se dirige a um deus (Priapo) para afastar o amor por outro pastor (Dáfnis). É possível, portanto, esquematizar a sequência, em que o poeta-pastor por excelência está sempre presente, da seguinte maneira: homem-deus; deuses-homem; homem-deus-homem, lembrando, por fim, a possível passagem de

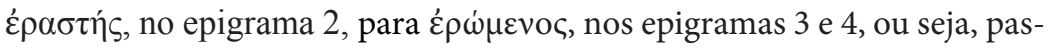
sa de "caçador" a "caçado".

52 Para a caracterização da espécie, vale destacar o locus amoenus (5-12), o endereçamento ao cabreiro (v. 1: aỉró $\varepsilon \varepsilon$ ) e a presença de Dáfnis (v. 14: $\Delta \dot{\alpha} \varphi v i \delta o ́ \varsigma)$.

53 Para o gênero, ver Oliva Neto 2006: 81-120; para os dois epigramas, ver esp. 86-88, em que enfatiza o "rebaixamento na elocução" dos poemas (sobre a elocução simples do epigrama 4, "quase prosaica", ver Rossi 2001: 161-163). Associa ainda o epigrama 3 aos epigramas descritivos, situados no livro 9 da Antologia Palatina (ver imagem a que se associa em Oliva Neto 2006: 147, figura 45). Para a discussão da classificação como “descritivo", ver Rossi 2001: 141146; 153-154 (para o epigrama 4).

54 Priapo concorre para o ridículo do epigrama.

55 Ver Rossi 2001: 163-165; Oliva Neto 2006: 199, n. 44.

56 Para mistura de gêneros, ver Rossi 1971: 84-86. Nos textos críticos, para designar mescla genérica, é convencional usar a expressão "Kreuzung der Gattungen", cunhada por Wilhelm

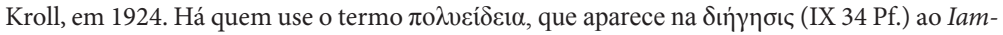
bo 13 de Calímaco (fr. 203 Pf.). No entanto, não é claro na passagem se a variedade genérica se refira apenas ao livro de Iambos ou a toda obra do poeta. Para a discussão, em que se defende a última interpretação, ver Dawson 1950: 130 e ss. e Fantuzzi 1991: 47-51, retomados por Lelli 2004: 125-127, e Scodel 1987: 208, retomada por Acosta-Hughes 2002: 82-89. Para a primeira interpretação, ver Rossi 1971: 83-84 e Kerkhecker 1999: 262. Seja como for, a polêmica de Calímaco, que defende a $\pi 0 \lambda v \varepsilon i ́ \delta \varepsilon 1 \alpha$ e a poesia produzida pela $\tau \varepsilon \dot{\chi} \chi \eta$, faz referência a um passo do Íon de Platão (531e-534e), em que se diz ser o poeta, inspirado pela Musa, capaz de compor bem em um único gênero. 


\section{Dáfnis, o Vaqueiro}

No último poema em que se menciona Dáfnis, que, junto com outros pastores, acordará Pã (epigrama 5), volta-se à sua primeira aparição (epigrama 2), em que Dáfnis dedica seus instrumentos a Pã, concluindo com fechamento em anel a presença, na recolha epigramática, do poeta-pastor. No entanto, Dáfnis agora está caracterizado de maneira tradicional, como vaqueiro ou boiadeiro (v.3: $\beta \omega \kappa o ́ \lambda o \varsigma)$, já não como caçador, a exemplo dos epigramas anteriores (2 e 3$)$ :

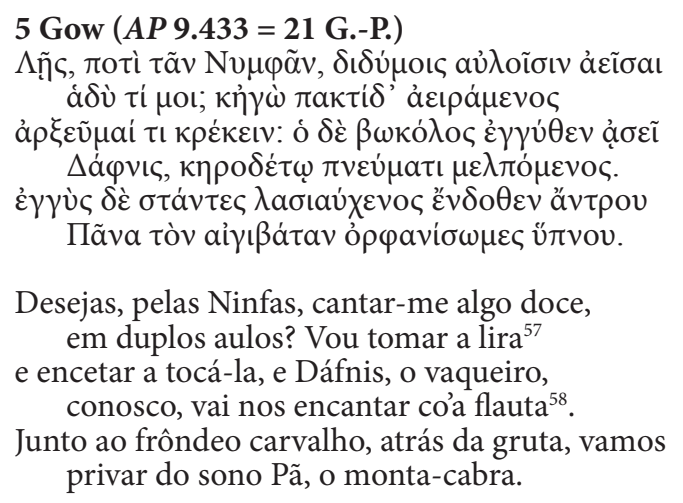

Este epigrama é exemplo, mais uma vez, de mistura genérica, em que a matéria bucólica se insere no epigrama em forma de convite, característica dos epigramas simpóticos, como descrito por Rossi (2001: 170) ${ }^{59}$.

Um aspecto, porém, ainda não comentado na sequência dos epigramas em que aparece o pastor Dáfnis (2-5) é o progressivo afastamento da cena principal, como marca editorial: no epigrama 2, Dáfnis, primeira palavra do poema, dedica seus instrumentos a Pã; no epigrama 3, o papel ativo já não é do pastor, que dorme, mas dos deuses, Pã e Priapo, que o procuram; no epigrama 4, novamente, Dáfnis já não tem papel ativo, mas, ao contrário, um cabreiro pede que Priapo o livre do amor que tem por Dáfnis; no epigrama 5, dois pastores ocupam a cena e menciona-se que Dáfnis se juntará a eles para despertar Pã.

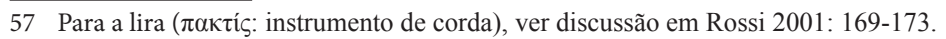

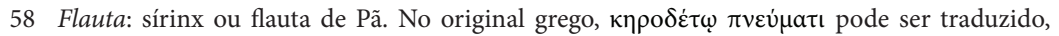
de modo mais literal, "com o sopro das canas ligadas por cera". Deixei de lado na tradução $\mu \varepsilon \lambda \pi$ tó $\mu \varepsilon v o \varsigma$ ("cantando").

59 Menciona um epigrama de Filodemo (AP 11.44), que pode ter sido modelo para o poema 13 de Catulo, em que convida, jocosamente, Fabulo para um banquete. 
Outra marca editorial ainda não observada é a alternância ${ }^{60}$ neste conjunto em que aparece o poeta-pastor por excelência: se, por um lado, pode-se relacionar o epigrama 2 (oferendas a Pã) com o 4 (oferendas a Priapo), em que há características do gênero votivo, há, por outro lado, elementos narrativos ${ }^{61}$ nos epigramas 3 e 5 que os unem: no primeiro, Dáfnis dorme, enquanto Pã e Priapo o procuram; no segundo, Pã dorme, enquanto os pastores, inclusive Dáfnis, se preparam para acordá-lo.

Por fim, destaca-se neste ciclo de epigramas dedicado a Dáfnis, que ele aparece representado como cantor no início, epigrama 2.1-2, em que canta na bela siringe bucólico hino, e no fim, epigrama 5.3-6, em que vai se juntar a outros pastores para despertar Pã com música.

\title{
A Morte Como Conclusão
}

Não parece convincente ${ }^{62}$ a relação do epigrama 5 com o epigrama 6, comentada por Gutzwiller (1998: 43-44), que se vale do Idílio 1 de Teócrito, presente como modelo em ambos ${ }^{63}$. O primeiro verso do epigrama $5(\Lambda \tilde{\eta} \varsigma$,

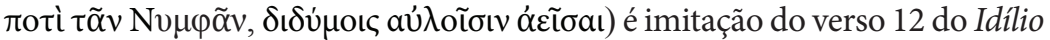

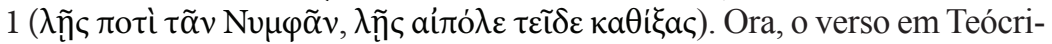
to é pronunciado por Tírsis, e, portanto, o epigrama 5 prepararia o epigrama 6 , em que a persona loquens se dirige a Tírsis, triste pela perda da cabrita:

\author{
$6(A P 9.432=22$ G.-P. $)$

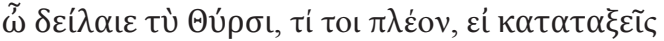

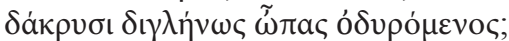

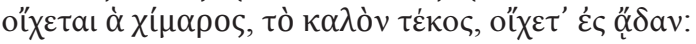

60 Para esta característica na organização nos Iambi de Calímaco, ver Kerkhecker 1999: 284285, em que relaciona os iambos 2 e 4, de um lado, em que se usa o aĩvo 5 , de outro, em que há matéria erótica. Para a relação entre os iambos 2 e 4 , ver também Acosta-Hughes e Scodel 2004: 9-12. Em âmbito latino (ver Nisbet e Hubbard 1978: 5), no segundo livro das Odes de Horácio, alternam-se estrofes alcaicas e sáficas até 2.11, como é bem conhecido; nas Bucólicas de Vergílio e Calpúrnio, alternam-se éclogas dramáticas e narrativas; na Priapéia latina, alternam-se (1-14) dísticos elegíacos e hendecassílabos falécios. Na própria recolha dos epigramas atribuídos a Teócrito, aparece de novo esta marca editorial (ver nota 12 acima).

61 Embora preocupada com outras questões, a observação é de Rossi 2001: 169: “Therefore, just as in the case of epigram 3, this composition [epigrama 5] should also be considered not descriptive, but narrative, since it recounts na episode, enumerating in order the sucession of its various phases".

62 A crítica já em Rossi 2001: 368: n. 32.

63 Ver Rossi 2001: 173-177, para o epigrama 5, e 184-186, para o epigrama 6. 


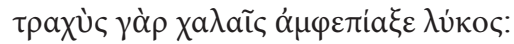

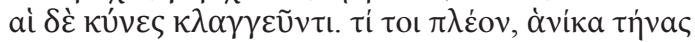

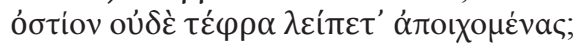

Ah, Tírsis infeliz, que proveito há se as duas

pupilas por tuas lágrimas consomes?

Foi-se a cabrita, a bela cria, foi-se para o Hades; cruel lobo em suas garras a prendeu.

Teus cães estão latindo: que proveito há quando dela não se deixou cinza nem osso?

É certo, porém, que no último epigrama da primeira seção, em que se misturam espécies (no caso a espécie bucólica à espécie fúnebre para animais $\left.{ }^{64}\right)$, Dáfnis já não está presente, e então surge o cabreiro Tírsis, que lamenta a morte da cabrita. Ora, independentemente da relação que se estabeleça com os epigramas precedentes, parece-me também aqui haver outra marca editorial: a morte como conclusão, comum no fechamento de seções de livros ou da obra ${ }^{65}$.

Por conseguinte, nesta primeira parte da $\sigma \cup \lambda \lambda o \gamma \eta \dot{~ d o s ~ e p i g r a m a s ~ a t r i-~}$ buídos a Teócrito, em que se ressaltou a mistura do bucólico com outras espécies epigramáticas, tal como a da Priapéia (epigramas 3 e 4), foi possível observar algumas marcas editoriais na organização dos poemas, tais como o proêmio (epigrama 1) e a conclusão (epigrama 6), que encerram os epigramas em que Dáfnis, o poeta-pastor por excelência, está presente (epigramas 2-5); a disposição por alternância de poemas que se relacionam pela matéria (epigramas 2 e 4, de um lado, com elementos votivos, e epigramas 3 e 5, de outro, com elementos descritivos e personagens dormindo).

\section{BIBLIOGRAFIA}

ACOSTA-HUGHES, B. Polyeideia: The Iambi of Callimachus and the archaic iambic tradition, Berkeley-Los Angeles: University of California Press, 2002.

64 Para a espécie, ver Gorla 1997, que constitui uma seção na AP (7.189-216, com o acréscimo de 364). Ver também Rossi 2001: 180-184.

65 Para a conclusão como morte, ver Fowler 2000: 247 e Hasegawa 2010: 12. Se, por um lado, encerra-se a seção com o epigrama fúnebre, alude, por outro, à forma original do gênero, ao evocar temas funerários. 
ACOSTA-HUGHES, B. e SCODEL, R. "Aesop poeta: Aesop and the fable in Callimachus'Iambi” In Callimachus II (Hellenistica Groningana, vol. VII), ed. by M. A. Harder, R. F. Regtuit and G. C. Wakker, Leuven: Peeters, 2004, 1-21. ARGENTIERI, L. "Epigramma e libro. Morfologia delle raccolte epigrammatiche premeleagree", ZPE 121 (1998), 1-20.

CANFORA, L. "La Biblioteca e il Museio" In Lo spazio letterario della Grecia antica (vol. I, tomo II), dir. G. Cambiano, L. Canfora e Diego Lanza, Roma: Salerno Editrice, 1993, 11-29.

DAWSON, C. M. “The Iambi of Callimachus. A Hellenistic poet's experimental laboratory”, YClS 11 (1950), 1-168.

DEGANI, E. "Lepigramma" In Lo spazio letterario della Grecia antica (vol. I, tomo II), dir. G. Cambiano, L. Canfora e Diego Lanza, Roma: Salerno Editrice, 1993, 197-233.

FANTUZZI, M. "Il sistema letterario della poesia alessandrina nel III sec. a.C.” In Lo spazio letterario della Grecia antica (vol. I, tomo II), dir. G. Cambiano, L. Canfora e Diego Lanza, Roma: Salerno Editrice, 1993, 31-72.

FANTUZZI, M. e HUNTER, R. Muse e modelli. La poesia ellenistica da Alessandro Magno ad Augusto, Roma/Bari: Laterza: 2002.

FOWLER, D. Roman constructions. Readings in postmodern Latin, Oxford: Oxford University Press, 2000.

GORLA, C. “La nascita dell'epitimbio Per animali: Anyte di Tegea e i SUOI CONTINUATORI", Acme 50 (1997), 33-60.

Gow, A.S.F. Theocritus, Cambridge: Cambridge University Press, 1952, vol. 2.

GOW, A.S.F e PAGE, D. The Greek anthology. Hellenistic epigrams, Cambridge: Cambridge University Press, 1965.

GUICHARD, L.A. Asclepiades de Samos: epigramas y fragmentos. Estudio introductorio, revisión del texto, traducción y comentario, Bern: Peter Lang, 2004.

GUTZWILLER, K. “The evidence for Theocritean poetry books” In Theocritus (Hellenistica Groningana, vol. II), ed. by M. A. Harder, R. F. Regtuit and G. C. Wakker, Groningen: Egbert Forsten Groningen, 1996a, 119-148. "Vergil and the date of the Theocritean epigram book", Philologus 140 (1996b), 92-9.

. Poetic garlands: Hellenistic epigrams in context, Berkeley/Los Angeles/London: University of California Press, 1998. HASEGAWA, A. Os limites do gênero bucólico em Vergílio: um estudo das éclogas dramáticas, Humanitas: São Paulo, 2012. 
Dispositio e distinção de gêneros nos Epodos de Horácio: estudo acompanhado de tradução em verso. Tese de doutorado. USP. 2010. HUNTER, R. Theocritus. A selection (Idylls 1, 3, 4, 6, 10, 11 and 13), Cambridge: Cambridge University Press, 1999.

KERKHECKER, A. Callimachus'book of Iambi, Oxford: Oxford University Press, 1999.

KREVANS, N. "The arrangement of epigrams in collections" In Hellenistic Epigram (Brill's Companion to) ed. by Peter Bing and Jon Steffen Bruss, Leiden/Boston: Brill, 2007, 131-146.

LARSON, J. "Astacides the goatherd (Callim. Epigr. 22 PF.)", CPh 92 (1997), 131-7.

LELLI, E. Critica e polemiche letterarie nei Giambi di Callimacho, Alessandria: Edizioni dell'Orso, 2004.

NISBET, R.G.M. E HubBARd, M. A commentary on Horace, Odes, Book II, Oxford: Oxford University Press, 1978.

OLIVA NETO, J.A. Falo no jardim: Priapéia grega, Priapéia latina, Cotia/ Campinas: Ateliê Editorial/Editora Unicamp, 2006.

PARDINI, A. "La ripartizione in libri dell'opera di Alceo", RFIC 119 (1991), 257-84.

PUELMA, M. "Epigramma: osservazioni sulla storia di um termine greco-latine”, Maia 49 (1997), 189-213.

ROSSI, L. The epigrams ascribed to Theocritus: a method of approach (Hellenistica Groningana), Leuven: Peeters, 2001.

SCODEL, R. "Horace, Lucilius and Callimachean polemic", HSPh 91 (1987), 199-215.

SENS, A. Asclepiades of Samos: epigrams and fragments, Oxford: Oxford University Press, 2011.

STANZEL, K-H. "Bucolic epigram” In Hellenistic epigram (Brill's

Companion to) ed. by Peter Bing and Jon Steffen Bruss, Leiden/Boston: Brill, 2007, 333-351.

TARDITI, G. "Per uma lettura degli epigrammatisti greci”, Aevum antiquum 1 (1988), 5-75.

TORRANO, JAA (estudo e tradução). Hesíodo. Teogonia: a origem dos deuses, São Paulo: Iluminuras, 1995.

WILAMOWITZ-MOELLENDORFF, U. von. Die Textgeschichte der griechischen Bukoliker (Philologische Untersuchungen 18), Berlin, 1906.

Recebido em: 30/11/2015. Aceito em: 01/03/2016. 